\title{
Artificial microRNA-mediated resistance against the monopartite begomovirus Cotton leaf curl Burewala virus
}

\author{
Irfan Ali, Imran Amin, Rob W Briddon and Shahid Mansoor
}

\begin{abstract}
Background: Cotton leaf curl disease, caused by single-stranded DNA viruses of the genus Begomovirus (family Geminiviridae), is a major constraint to cotton cultivation across Pakistan and north-western India. At this time only cotton varieties with moderate tolerance are available to counter the disease. microRNAs (miRNAs) are a class of endogenous small RNA molecules that play an important role in plant development, signal transduction, and response to biotic and a biotic stress. Studies have shown that miRNAs can be engineered to alter their target specificity. Such artificial miRNAs (amiRNAs) have been shown to provide resistance against plant-infecting viruses.
\end{abstract}

Results: Two amiRNA constructs, based on the sequence of cotton miRNA169a, were produced containing 21 nt of the V2 gene sequence of Cotton leaf curl Burewala virus (CLCuBuV) and transformed into Nicotiana benthamiana. The first amiRNA construct (P1C) maintained the miR169a sequence with the exception of the replaced $21 \mathrm{nt}$ whereas in the second (P1D) the sequence of the miRNA169a backbone was altered to restore some of the hydrogen bonding of the mature miRNA duplex. P1C transgenic plants showed good resistance when challenge with CLCuBV; plants being asymptomatic with low viral DNA levels. The resistance to heterologous viruses was lower and correlated with the numbers of sequence mismatches between the amiRNA and the V2 gene sequence. P1D plants showed overall poorer resistance to challenge with all viruses tested.

Conclusions: The results show that the amiRNA approach can deliver efficient resistance in plants against a monopartite begomoviruses and that this has the potential to be broad-spectrum, providing protection from a number of viruses. Additionally the findings indicate that the levels of resistance depend upon the levels of complementarity between the amiRNA and the target sequence and the sequence of the miRNA backbone, consistent with earlier studies.

\section{Background}

RNA interference (RNAi; also known as RNA silencing) is a general phenomenon in eukaryotes that plays diverse roles including defense against pathogens. The key features of RNAi include the production of 21-25 nt small RNAs (sRNA) by enzymes known as Dicers [1] and the formation of RNA-induced silencing complexes (RISCs) which contain Argonaute (Ago) proteins that directly carry out gene silencing at the transcriptional or posttranscriptional levels [2-5]. There are two major classes of sRNAs involved in RNAi, small interfering RNAs (siRNAs) and microRNAs (miRNAs). siRNAs result

\footnotetext{
*Correspondence: shahidmansoor7@gmail.com

Agricultural Biotechnology Division, National Institute for Biotechnology and Genetic Engineering, PO Box 577, Jhang Road, Faisalabad, Pakistan
}

from the action of dicers on large double-stranded RNAs which have diverse origins. miRNAs are transcribed from their own genes or from introns and from foldback structures with regions that are double stranded. In plants these primary-miRNAs are processed by the action of dicers into the precursor-miRNA (premiRNA) and then miRNA:miRNA* duplexes in the nucleus before being exported for incorporation into RISCs (miRNA* indicating the strand not incorporated into RISC).

Cotton leaf curl disease (CLCuD) is a major constraint to cotton production across Pakistan and north-western India. The disease is caused by monopartite begomoviruses, the most important of which at this time is Cotton leaf curl Burewala virus (CLCuBuV), in association with a

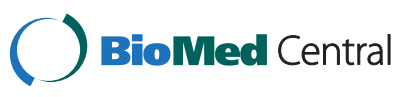


specific satellite [6]. Viruses of the genus Begomovirus (family Geminiviridae) have circular single-stranded DNA genomes and are transmitted by the whitefly Bemisia tabaci [7]. Although in the Old World a small number of begomoviruses have been identified, with genomes consisting of two ssDNA circles (known as DNA A and DNA

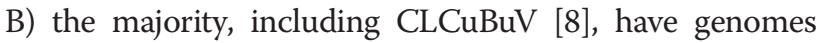
consisting of a single component which is a homolog of the DNA A of bipartite viruses. The genomes of monopartite (and DNA A components of bipartite) begomoviruses encode genes in both orientations. The virion-sense strand encodes the coat protein and the V2 gene whereas genes encoded on the complementary-sense strand are involved in viral DNA replication, regulating host and viral gene expression and overcoming host defences $[7,8]$.

Following the demonstration by Vaucheret et al. [9] that changes in the sequences of mature miRNAs does not affect their biogenesis and the use of modified miRNAs (referred to as artificial-miRNA [amiRNAs]) to target viruses by Niu et al. [10] several studies have been successful in generating resistance to phytopathogenic viruses using amiRNA. Most recently this approach has been successfully applied to a bipartite begomovirus [11]. This has the advantage over approaches that rely on the production of siRNAs, which usually involve quite long virus derived sequences, that only short sequences are required, thus reducing the chances of recombination between the transgenic sequence and the infecting virus. Moreover, use of a $21 \mathrm{nt}$ sequence derived from a begomovirus may avoid silencing of the transgene by the invading virus, as has been reported previously [12]. Here the amiRNA approach has for the first time been investigated as a means of generating resistance to a monopartite begomovirus.

\section{Results}

Production and analysis of transgenic $N$. benthamiana plants harbouring amiRNA

The amiRNA produced were based upon the sequence of the pre-miRNA169a (Figure 1A; [13]). For construct $\mathrm{P} 1 \mathrm{C}$ the $21 \mathrm{nt}$ of pre-miRNA169a that form the mature miRNA were replaced with $21 \mathrm{nt}$ of the sequence of the V2 gene of $\mathrm{CLCuBuV}$ without any further changes (Figure 1C). For construct P1D the same change as in P1C was made but additionally sequence changes were introduced into the sequence of the backbone of pre-miRNA 169a (in the sequence that forms the passenger strand [miRNA*] of the mature miRNA duplex) to restore some of the hydrogen bonding in the predicted structure of the pre-miRNA lost by introducing the CLCuBuV sequences
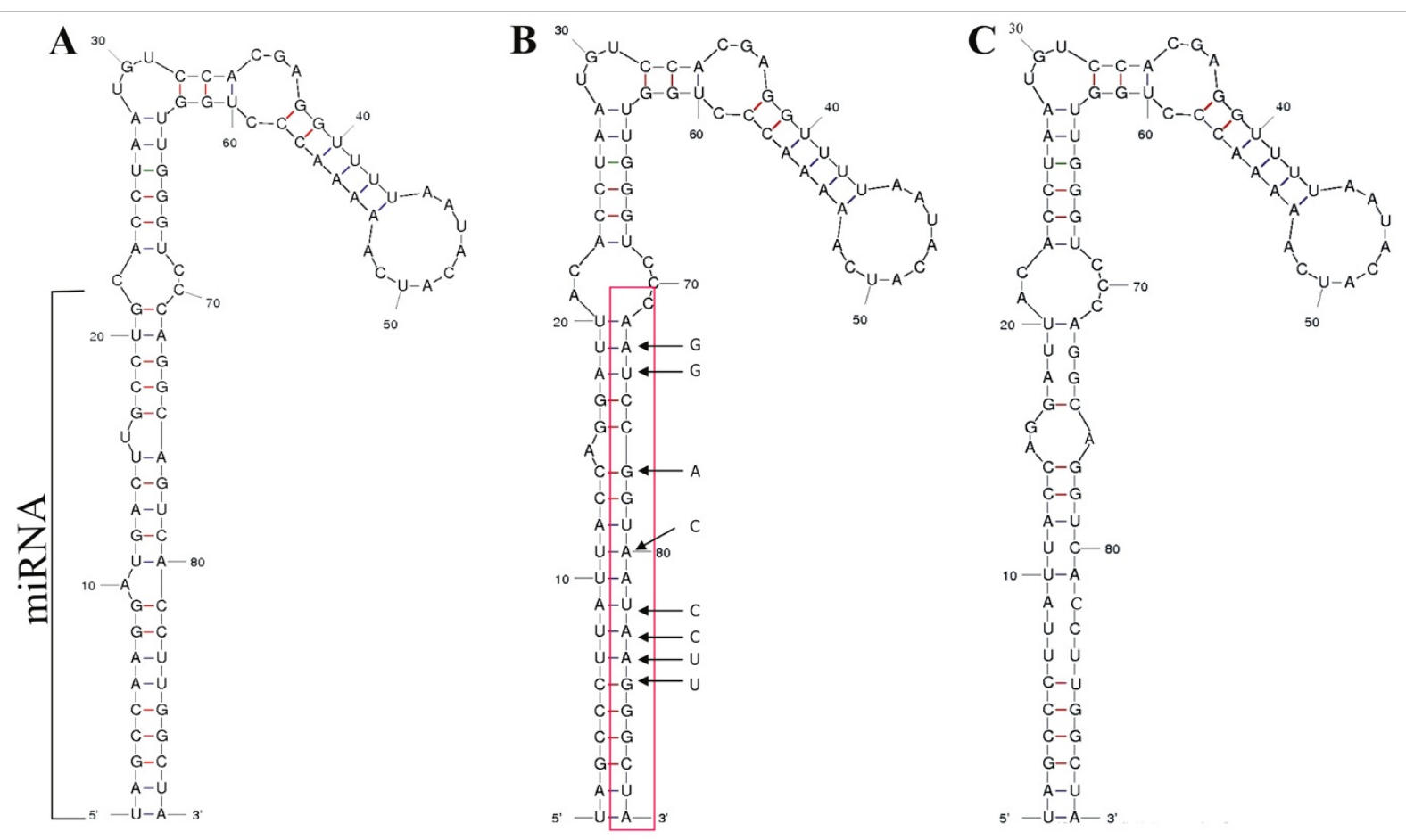

Figure 1 Predicted secondary structures of pre-miRNAs. The predicted structures of pre-miRNA169a (A), pre-amiRNA P1D (B) and pre-amiRNA P1C (C) are shown. For pre-miRNA169a the sequence which forms the mature miRNA is indicated. For the amiRNA this will be the introduced sequence of CLCUBUV. The region of sequence into which changes were introduced into pre-amiRNA P1D to maintain a structure similar to pre-miRNA169a is highlighted by a red box. The nucleotide replaced in the miRNA* sequence are shown by arrows. 
(Figure 1B). The introduced sequences are near the center of the V2 gene (coordinates 265-285 of CLCuBuV; EMBL Accession No. AM421522) spanning the area encoding amino acids $46-51$ of the predicted 118 amino acid V2 protein.

\section{The amiRNA constructs were transformed into $N$.} benthamiana by Agrobacterium-mediated transformation

A total of 13 Kanamycin resistant primary transformed $N$. benthamiana plants were obtained from the transformation (7 transformed with the P1C construct and 6 with P1D). However, PCR analysis for the presence of the amiRNA indicated that only $3 \mathrm{P} 1 \mathrm{C}$ and 4 P1D plants contained the transgene. These were progressed to the $\mathrm{T} 2$ generation by self-pollination and selection of resulting seed on Kanamycin. In the T3 generation a single line for each construct that did not show segregation was selected for virus inoculation. Southern blot analysis of these plants by digestion of extracted DNA with a restriction enzyme that cuts once within the transgene and probing with an NptII gene fragment yielded single bands, suggestive of single integration sites for each line (results no shown).

\section{Challenge inoculation with CLCuBuV}

The first symptoms of infection, mild downward curling of newly developing leaves, were visible on non-transgenic $N$. benthamiana plants inoculated with $\mathrm{CLCuBuV}$ at 15 days post inoculation (dpi). By 28 dpi all nontransgenic $N$. benthamiana plants showed symptoms of infection consisting of downward leaf curling and some crumpling of newly developing leaves (Figure 2A, panel 1).

For CLCuBuV inoculated transgenic $N$. benthamiana plants harbouring P1C a small number of plants (3 out of 20 plants inoculated) showed very mild symptoms at 15 dpi (Figure 2A, panel 2). However, these symptoms did not develop into the severe symptoms shown by non-transgenic plants, with all subsequently developing leaves showing no symptoms. PCR analysis showed the majority of plants (19 out of 20) contain viral DNA (Table 1). Southern blot analysis of DNA extracted from inoculated plants showed that plants that ex hibited the initial mild symptoms contained slightly more viral DNA than plants that remained asymptomatic (Figure 3, panel A, lanes 1 and 2). However, the transgenic plants all contained significantly lower viral DNA levels than infected, non-transgenic plants (Figure 3, panel A, lane 6).

P1D transgenic $N$. benthamiana plants inoculated with CLCuBuV showed the first mild symptoms of infection at $15 \mathrm{dpi}$ in a small number of plants (5 out of 20 plants inoculated). However, these plants did not continue to show severe symptoms with all newly developing leaves showing very mild leaf curling (18/20). All other plants remained symptomless throughout (Figure 2B, panel 2). Southern

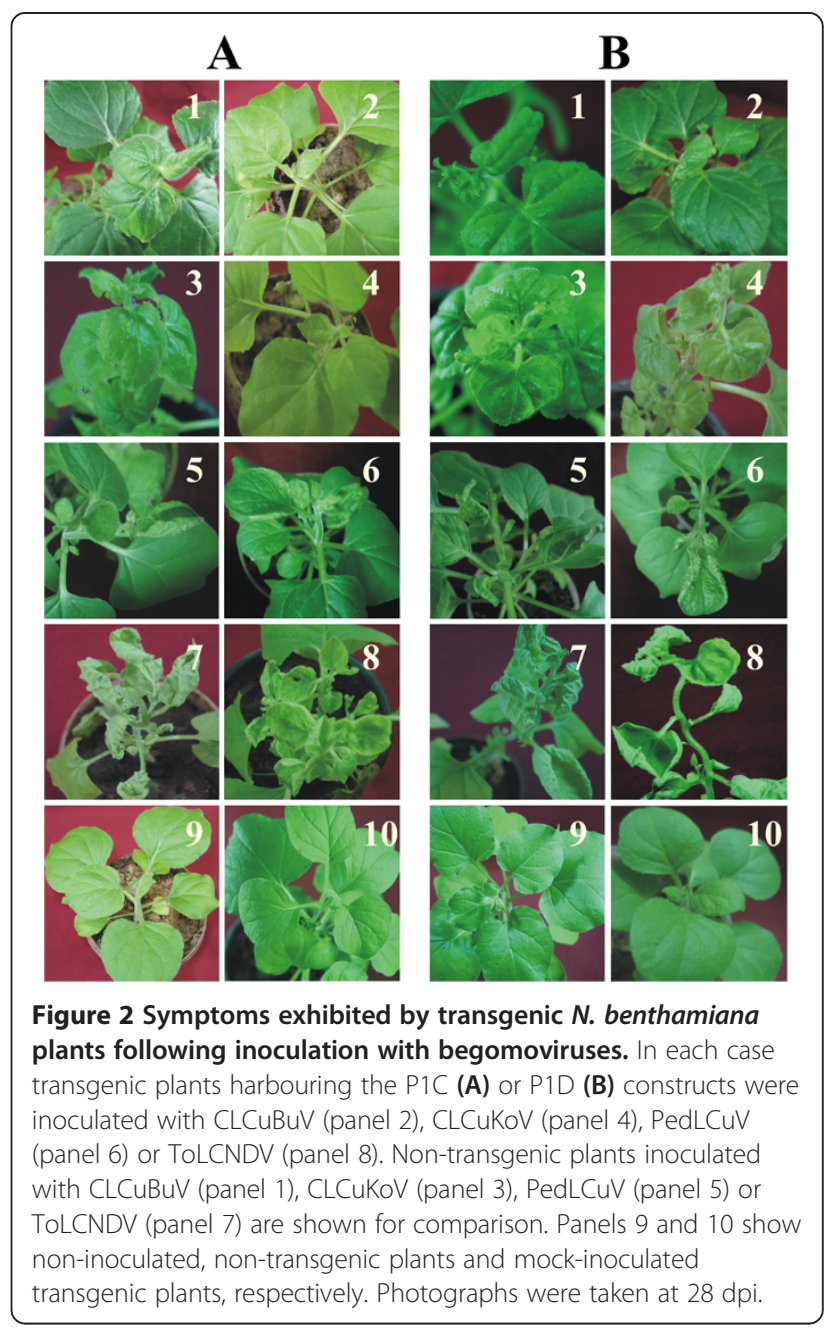

blot hybridization showed the presence of viral DNA at levels below those detected in infected, non-transgenic plants (Table 1).

\section{Challenge inoculation with Cotton leaf curl Kokhran virus}

For non-transgenic $N$. benthamiana plants inoculated with Cotton leaf curl Kokhran virus (CLCuKoV) the first symptoms of infection, consisting of a mild downward leaf curling of the edges of newly developing leaves, were observed at $21 \mathrm{dpi}$. All non-transgenic plants developed severe downward leaf curling symptoms in newly developing leaves by 28 dpi (Figure 2A, panel 3).

None of the transgenic $N$. benthamiana plants harbouring the P1C construct developed symptoms following inoculation with $\mathrm{CLCuKoV}$ (Figure 2A, panel 4). However, diagnostic PCR with primers CLCKV2F and CLCKV2R showed the presence of viral DNA in young, newly developing leaves even though no viral DNA could be detected by Southern blot hybridization (Figure 3b; 
Table 1 Infectivity of CLCuBuV in transgenic $\boldsymbol{N}$. benthamiana plants harbouring amiRNA

\begin{tabular}{|c|c|c|c|c|c|c|c|}
\hline \multirow[t]{4}{*}{ Plant } & \multicolumn{4}{|c|}{ Infectivity } & \multirow{2}{*}{\multicolumn{3}{|c|}{ Diagnostics }} \\
\hline & \multicolumn{4}{|c|}{$\begin{array}{c}\text { (plants symptomatic/plants } \\
\text { inoculated) }\end{array}$} & & & \\
\hline & \multicolumn{2}{|c|}{ Exp. 1} & \multicolumn{2}{|c|}{ Exp.2 } & \multicolumn{2}{|c|}{$\mathrm{PCR}^{\mathrm{f}}$} & \multirow[t]{2}{*}{ Southern $^{\$}$} \\
\hline & 15dpi & 28dpi & 15dpi & 28dpi & Exp. 1 & Exp.2 & \\
\hline$\overline{N . b}$ & $8 / 10$ & $10 / 10$ & $10 / 10$ & $10 / 10$ & $9 / 10$ & $10 / 10$ & ++++ \\
\hline $\mathrm{P} 1 \mathrm{C}$ & $2 / 10$ & $0 / 10$ & $1 / 10$ & $0 / 10$ & $10 / 10$ & $10 / 10$ & + \\
\hline P1D & $3 / 10$ & $8 / 10$ & $2 / 10$ & $10 / 10$ & $10 / 10$ & $10 / 10$ & +++ \\
\hline$N \cdot b^{*}$ & $0 / 10$ & $0 / 10$ & $0 / 10$ & $0 / 10$ & $0 / 10$ & $0 / 10$ & ND \\
\hline$N \cdot b^{\#}$ & $0 / 5$ & $0 / 5$ & $0 / 5$ & $0 / 5$ & $0 / 5$ & $0 / 5$ & - \\
\hline
\end{tabular}

* Non-transgenic $N$. benthamiana plants inoculated with Agrobacterium cultures harbouring pGreen0029.

\# Non-inoculated plants.

${ }^{£}$ CLCuBuV was detected in nucleic acids extracted from plants by PCR using primers IRVF and IRVR (Table 5).

$\$$ Southern hybridization results are given as strong hybridization $(++++)$, through weak hybridization (+), to no hybridization detected (-). Some plants were not examined for the presence of virus by hybridization (ND).

Table 2). This suggests that viral DNA levels were below the detection threshold for hybridization.

The first symptoms of infection on transgenic $N$. ben thamiana plants harbouring P1D following inoculation with CLCuKoV were visible in a small number of plants at $21 \mathrm{dpi}$ and the majority of plants showed severe symptoms of infection by $28 \mathrm{dpi}$ (Figure 2B, panel 4; Table 2). Southern blot analysis showed the presence of significant amounts of viral DNA in P1D transgenic plants, although this was lower than the levels of viral DNA detected in infected, non-transgenic plants (Figure 3, panel B).

\section{Challenge inoculation with Pedilanthus leaf curl virus}

The first symptoms of infection, a mild upward curling of the edges of newly developing leaves, in non-transgenic $N$. benthamiana plants inoculated with Pedilanthus leaf curl virus (PedLCuV) were visible at $15 \mathrm{dpi}$. By $21 \mathrm{dpi}$ all nontransgenic plants exhibited severe symptoms consisting of upward leaf curling, vein thickening and leaf shortening (Figure 2A, panel 5; Table 3).

Mild symptoms of infection appeared in 3 out 10 inoculated transgenic plants harbouring $\mathrm{P} 1 \mathrm{C}$ construct but all the plants showed severe symptoms by $21 \mathrm{dpi}$ (Figure 2A, panel 6). In contrast, for plants transformed with the P1D construct, all inoculated plants showed initial mild symptoms at $15 \mathrm{dpi}$ and severe symptoms by $21 \mathrm{dpi}$ (Figure 2B, panel 6; Table 3). Southern blot hybridization of genomic DNA extracted from systemic leaves showed the accumulation of high levels of viral DNA in nontransgenic and P1D transgenic $N$. benthamiana plants (Figure 3, panel C). However, in transgenic plants har boring P1C possibly slightly less viral DNA accumulated than in non-transgenic plants.

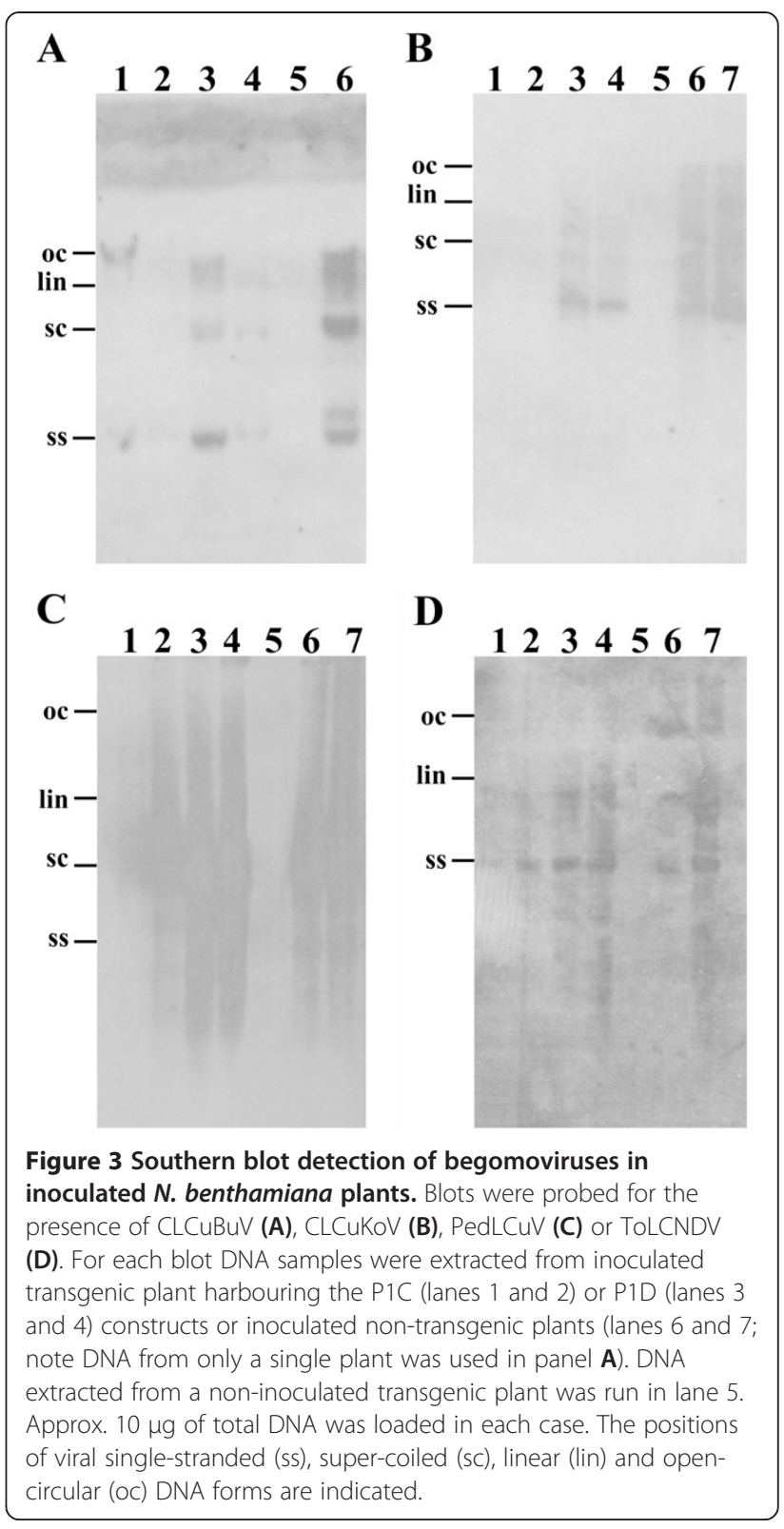

\section{Challenge inoculation with Tomato leaf curl New Delhi virus}

Non-transgenic $N$. benthamiana plants inoculated with the bipartite Tomato leaf curl New Delhi virus (ToLCNDV) showed the first symptoms of infection, mild leaf curling, at $15 \mathrm{dpi}$. By $21 \mathrm{dpi}$ all plants were symptomatic showing upward leaf curling, leaf yellowing, vein thickening and a reduction in leaf size (Figure $2 \mathrm{~A}$, panel 7).

All transgenic plants inoculated with ToLCNDV behaved like the non-transgenic plants with initial symptoms appearing at $15 \mathrm{dpi}$ and full symptoms in all plants developing by 21 dpi (Figure 2A, panel 8; Figure 2B, panel 8; Table 4). Southern blot analysis of inoculated plants showed the levels of ToLCNDV DNA in transgenic plants 
Table 2 Infectivity of CLCuKoV in transgenic $N$. benthamiana plants harbouring amiRNA

\begin{tabular}{|c|c|c|c|c|c|c|c|}
\hline \multirow[t]{4}{*}{ Plant } & \multicolumn{4}{|c|}{ Infectivity } & \multicolumn{3}{|c|}{ Diagnostics } \\
\hline & \multicolumn{4}{|c|}{$\begin{array}{l}\text { (plants symptomatic/plants } \\
\text { inoculated) }\end{array}$} & \multirow{2}{*}{\multicolumn{2}{|c|}{$\mathrm{PCR}^{\mathrm{f}}$}} & \multirow{3}{*}{ Southern } \\
\hline & \multicolumn{2}{|c|}{ Exp. 1} & \multicolumn{2}{|c|}{ Exp.2 } & & & \\
\hline & 15dpi & 28dpi & 15dpi & 28dpi & Exp. 1 & Exp.2 & \\
\hline N. $b$ & $0 / 10$ & $10 / 10$ & $1 / 10$ & $10 / 10$ & $10 / 10$ & $10 / 10$ & ++++ \\
\hline P1C & $0 / 10$ & $1 / 10$ & $0 / 10$ & $0 / 10$ & $10 / 10$ & $10 / 10$ & + \\
\hline P1D & $0 / 10$ & $8 / 10$ & $0 / 10$ & $10 / 10$ & $10 / 10$ & $10 / 10$ & ++ \\
\hline$N \cdot b^{*}$ & $0 / 10$ & $0 / 10$ & $0 / 10$ & $0 / 10$ & $0 / 10$ & $0 / 10$ & ND \\
\hline$N \cdot b^{\#}$ & $0 / 5$ & $0 / 5$ & $0 / 5$ & $0 / 5$ & $0 / 5$ & $0 / 5$ & - \\
\hline
\end{tabular}

* Non-transgenic $N$. benthamiana plants inoculated with Agrobacterium cultures harbouring pGreen 0029 .

\# Non-inoculated plants.

${ }^{\mathrm{E}} \mathrm{CLCuKoV}$ was detected in nucleic acids extracted from plants by PCR using primers CLCKV2F and CLCKV2R (Table 5).

$\$$ Southern hybridization results are given as strong hybridization $(++++)$, through weak hybridization (+), to no hybridization detected (-). Some plants were not examined for the presence of virus by hybridization (ND).

harbouring the P1D construct to be approximately equal to the levels of viral DNA detected in non-transgenic plants (Figure 3, panel E). However, for transgenic plants harbouring the P1C construct, the levels of ToLCNDV DNA were possibly marginally lower.

\section{Discussion}

Since the phenomenon was first identified RNAi has become the strategy of choice in efforts to develop transgenic resistance against viruses in plants. The siRNA strategy has been shown to be widely applicable against phytopathogenic viruses, including geminiviruses [14]. More recently engineered miRNAs have been investigated as a means of obtaining resistance following the demonstration that the

Table 3 Infectivity of PedLCuV in transgenic $\boldsymbol{N}$. benthamiana plants harbouring amiRNA

\begin{tabular}{|c|c|c|c|c|c|c|c|}
\hline \multirow[t]{4}{*}{ Plant } & \multicolumn{4}{|c|}{ Infectivity } & \multirow{2}{*}{\multicolumn{3}{|c|}{ Diagnostics }} \\
\hline & \multicolumn{4}{|c|}{$\begin{array}{l}\text { (plants symptomatic/plants } \\
\text { inoculated) }\end{array}$} & & & \\
\hline & \multicolumn{2}{|c|}{ Exp. 1} & \multicolumn{2}{|c|}{ Exp.2 } & \multicolumn{2}{|c|}{$P{ }^{ \pm}$} & \multirow[t]{2}{*}{ Southern } \\
\hline & 15dpi & 28dpi & 15dpi & 28dpi & Exp. 1 & Exp.2 & \\
\hline N. $b$ & $10 / 10$ & $10 / 10$ & $10 / 10$ & $10 / 10$ & $10 / 10$ & $10 / 10$ & ++++ \\
\hline P1C & $3 / 10$ & $10 / 10$ & $1 / 10$ & $10 / 10$ & $10 / 10$ & $10 / 10$ & +++ \\
\hline P1D & $8 / 10$ & $10 / 10$ & $10 / 10$ & $10 / 10$ & $10 / 10$ & $10 / 10$ & ++++ \\
\hline N. $b^{*}$ & $0 / 10$ & $0 / 10$ & $0 / 10$ & $0 / 10$ & $0 / 10$ & $0 / 10$ & ND \\
\hline$N \cdot b^{\#}$ & $0 / 5$ & $0 / 5$ & $0 / 5$ & $0 / 5$ & $0 / 5$ & $0 / 5$ & - \\
\hline
\end{tabular}

* Non-transgenic N. benthamiana plants inoculated with Agrobacterium cultures harbouring pGreen0029.

\# Non-inoculated plants.

${ }^{\mathrm{f}}$ PedLCUV was detected in nucleic acids extracted from plants by PCR using primers PedLCVV2F and PedLCuVV2R (Table 5).

$\$$ Southern hybridization results are given as strong hybridization $(++++)$, through weak hybridization (+), to no hybridization detected (-). Some plants were not examined for the presence of virus by hybridization (ND).
Table 4 Infectivity of ToLCNDV in transgenic $N$. benthamiana plants harbouring amiRNA

\begin{tabular}{|c|c|c|c|c|c|c|c|}
\hline \multirow[t]{4}{*}{ Plant } & \multicolumn{4}{|c|}{ Infectivity } & \multicolumn{3}{|c|}{ Diagnostics } \\
\hline & \multicolumn{4}{|c|}{$\begin{array}{l}\text { (plants symptomatic/plants } \\
\text { inoculated) }\end{array}$} & & & \\
\hline & \multicolumn{2}{|c|}{ Exp. 1} & \multicolumn{2}{|c|}{ Exp.2 } & \multicolumn{2}{|c|}{$\mathrm{PCR}^{\mathrm{f}}$} & \multirow[t]{2}{*}{ Southern } \\
\hline & 15dpi & 28dpi & 15dpi & 28dpi & Exp. 1 & Exp.2 & \\
\hline N. $b$ & $10 / 10$ & $10 / 10$ & $9 / 10$ & $10 / 10$ & $10 / 10$ & $10 / 10$ & ++++ \\
\hline P1C & 9/10 & $10 / 10$ & $7 / 10$ & $10 / 10$ & $10 / 10$ & $10 / 10$ & +++ \\
\hline P1D & $10 / 10$ & $10 / 10$ & $10 / 10$ & $10 / 10$ & $10 / 10$ & $10 / 10$ & ++++ \\
\hline$N . b^{*}$ & $0 / 10$ & $0 / 10$ & $0 / 10$ & $0 / 10$ & $0 / 10$ & $0 / 10$ & - \\
\hline$N \cdot b^{\#}$ & $0 / 5$ & $0 / 5$ & $0 / 5$ & $0 / 5$ & $0 / 5$ & $0 / 5$ & - \\
\hline
\end{tabular}

* Non-transgenic N. benthamiana plants inoculated with Agrobacterium cultures harbouring pGreen0029.

\# Non-inoculated plants.

${ }^{£}$ ToLCNDV was detected in nucleic acids extracted from plants by PCR using primers ToLCNDVV2F and ToLCNDVV2R (Table 5).

$\$$ Southern hybridization results are given as strong hybridization $(++++)$, through weak (+) hybridization to no hybridization detected (-).

targeting sequences pre-miRNAs could be modified [10] This approach has been shown to effectively deliver resistance against viruses including, most recently, the bipartite begomovirus ToLCNDV [11,15,16]. The results obtained here show for the first time that the amiRNA may also deliver resistance against monopartite begomoviruses.

The P1C amiRNA construct delivered efficient resistance against both $\mathrm{CLCuBuV}$ and $\mathrm{CLCuKoV}$. The majority of plants remained symptomless and the few plants that developed mild symptoms initially proceeded to lose those symptoms. Nevertheless, all CLCuBuV inoculated P1C plants were shown to contain viral DNA by PCR but (at least for plants that did not show the initial symptoms) the levels of DNA were below the detection threshold of Southern blot hybridization and significantly lower than infected non-transgenic control plants.

Less efficient resistance in P1C plants was evident to PedLCuV and ToLCNDV infections. Plants inoculated with PedLCuV showed delayed symptoms, although ultimately the viral DNA levels were high but lower than in non-transgenic plants. Inoculation of P1C plants with ToLCNDV had no apparent effects on the timing of symptom appearance or symptom severity. Nevertheless in some plants the levels of viral DNA were lower than in infected non-transgenic plants. An alignment of the V2 (AV2 for ToLCNDV) gene sequences homologous to those of the amiRNA of the four begomoviruses is shown in Figure 4. This shows the sequences of the V2 genes of the $\mathrm{CLCuBuV}$ and $\mathrm{CLCuKoV}$ to be identical in the region targetted by the P1C amiRNA. In contrast the V2 of PedLCV and the AV2 of ToLCNDV show mismatches (5 nucleotides for PedLCuV and 9 for ToLCNDV). The relative levels of resistance detected thus correlates with the levels of sequence identity, consistent with RNAi being homology dependent process [17]. 
CLCuBuV (AM421522) 265 TAATCCTGGTAATAAGGGCTA 285

CLCUKOV (AJ496286) 265 TAATCCTGGTAATAAGGGCTA 285

PedLCV (AM948961) 282 TGATTTCAGTAATAAGGGCTA 302

TOLCNDV (U15015) 260 TCATTCTTGTTCTCCGAGCAA 280

Figure 4 Alignment of the V2 gene sequences homologous to the amiRNA of the bogomoviruses used. Shown are the sequences of the V2 genes of Cotton leaf curl Burewala virus (CLCUBuV), Cotton leaf curl Kokhran virus (CLCuKoV) and Pedilanthus leaf curl virus (PedLCuV) as well as the AV2 gene of Tomato leaf curl New Delhi virus (ToLCNDV). Nucleotides differing from those of the CLCuBuV sequence are highlighted in red. Note that the sequences of amiRNAs P1C and P1D target (are complimentary to) the CLCuBuV sequence.

Overall the P1D amiRNA gave much poorer resistance although, with the possible exception of ToLCNDV, some symptom amelioration or reduction in viral DNA levels in plants was detected. This shows that the resistance resulting from amiRNA is influenced by the backbone sequence. This may be due to expression levels of the amiRNA or its interaction with Ago proteins, both of which have been shown to be affected by the sequence of the backbone $[14,18]$.

Mutation of the V2 gene of monopartite begomoviruses leads to viruses that induce infections that are nonsymptomatic with very low viral DNA levels [19-21], indicating that the $\mathrm{V} 2$ protein is a pathogenicity determinant and possibly involved in virus movement in plants. These features of V2 mutants are thus equivalent to the effects of silencing of the V2 gene using an amiRNA shown here. The product of the AV2 gene of bipartite begomoviruses is not essential for infectivity and mutation of these results in viruses that induce delayed but symptomatically normal infections [22], suggesting that this protein plays in part in, but is not essential for, virus movement; the essential virus-encoded proteins being encoded on the second component (DNA B; [23]). Although it is likely that the poor levels of resistance seen here to ToLCNDV are due to sequence differences with the amiRNA, it is also likely that part of the effect is due to complementation of the silenced AV2 gene functions by the DNA B. In light of this it is somewhat surprising that the amiRNA-mediated resistance targeting virion-sense genes of ToLCNDV reported by $\mathrm{Vu}$ et al. [11] resulted in either mild transient or no symptoms of infection. Possibly this is a host specific difference; the earlier study having used tomato whereas the study here used the highly permissive host $N$. benthamiana.

Manavella et al. [24] have shown that the use of 22 nt miRNA* or miRNA: miRNA* duplexes with asymmetric bulges can trigger transitivity-spread of the silencing outside the targeted sequence by the production of secondary siRNAs. Making use of this phenomenon may be useful in improving miRNA-mediated

Table 5 List of oligonucleotides primers used in the study

\begin{tabular}{|c|c|c|c|c|}
\hline Primer & Sequence $\left(5^{\prime}-3^{\prime}\right)$ & Virus/ Construct & Size of amplicon (bp) & Amplicon \\
\hline BAF & ACGCGTGCCGTGTTGCTGCCCCATTGTCC & \multirow{2}{*}{ begomovirus } & \multirow{2}{*}{$\sim 2800$} & \multirow{2}{*}{ genome } \\
\hline BAR & ACGCGTATGGGCTGYCGAAGTTSASACG & & & \\
\hline $\mathrm{BV} 2 \mathrm{~F}$ & ATGTGGGATCCACTGTTAAATGAG & \multirow{2}{*}{ CLCuBuV } & \multirow{2}{*}{356} & \multirow{2}{*}{ V2 gene } \\
\hline BV2R & TAGGAACATCTGGACTTCTGTAC & & & \\
\hline CLCKV2F & GTCGACAAGTATGCGTTGAAAAATGTG & \multirow{2}{*}{ CLCuKoV } & \multirow{2}{*}{370} & \multirow{2}{*}{ V2 gene } \\
\hline CLCKV2R & GGATCCACCTTCACATCCTCTAGGAAC & & & \\
\hline IRVF & CGTGGAATTCATGTGGGATCCACTGTT & \multirow{2}{*}{ CLCuBuV } & \multirow{2}{*}{348} & \multirow{2}{*}{ V2 gene } \\
\hline IRVR & TTCGTCGACGAACATCTGGACTTCTGTA & & & \\
\hline PedLCV2F & ATGTGGGATCCGTTATTGAAC & \multirow{2}{*}{ PedLCuV } & \multirow{2}{*}{357} & \multirow{2}{*}{ V2 gene } \\
\hline PedLCV2F & CTAGGAACATCTGGACTTCTG & & & \\
\hline TLCNDV2F & GTCGACAAACATGTGGGATCCATTATTGC & \multirow{2}{*}{ ToLCNDV } & \multirow{2}{*}{361} & \multirow{2}{*}{ AV2 gene } \\
\hline TLCNDV2R & CCCGGGCTTCTATACATTCTGTAC & & & \\
\hline P1CF & GACAGTGGTCCCAAAGATGGA & \multirow{2}{*}{$\mathrm{P} 1 \mathrm{C}$} & \multirow{2}{*}{273} & \multirow{2}{*}{ expression cassette ${ }^{*}$} \\
\hline P1CR & ATCGGGAATAATGGTCCTAA & & & \\
\hline P1DF & GACAGTGGTCCCAAAGATGGA & \multirow{2}{*}{ P1D } & \multirow{2}{*}{275} & \multirow{2}{*}{ expression cassette } \\
\hline P1DR & TAGCCCATATGCCCGGATTG & & & \\
\hline $35 \mathrm{SF}$ & GACAGTGGTCCCAAAGATGGA & \multirow{2}{*}{ plIT163 } & \multirow{2}{*}{150} & \multirow{2}{*}{ CaMV 355 promote } \\
\hline $35 S R$ & CAGTGGAGATATCACATCAATCCA & & & \\
\hline TLCNDBF & GTCCCGGGTATGTCACGTATCCATCA & \multirow{2}{*}{ ToLCNDV DNA B } & \multirow{2}{*}{550} & \multirow{2}{*}{ NSP gene } \\
\hline TLCNDBR & TATCGATTTATCCAATGTAATTAAGAAT & & & \\
\hline
\end{tabular}

* These primer pairs amplify from the 3' end of the CaMV 35S promoter (P1CF and P1DF) to the 3' end of the amiRNA construct (primers P1CR and P1DR being the reverse complement of the sequence of the amiRNA backbone [amiRNA* sequence]). 
resistance against geminiviruses with the possibility of inducing TGS and should be investigated in the further studies. Also targeting multiple transcripts with distinct amiRNA may yield improved resistance and reduce the chance of the resistance being broken by sequence changes in the virus.

The inability of the amiRNA to yield immunity, even against the homologous virus, suggests that this approach is unlikely to yield a durable resistance. Although virus levels are low in transgenic plants, the presence of replicating virus would allow mutations in the target sequence to accumulate leading, eventually, to a virus able to overcome the resistance. This is a problem with all homology-based resistance strategies and is particularly significant for the amiRNA approach, where only a short sequence is targeted. There are a number of possible ways of overcoming this problem. Firstly the durability may be improved by designing the amiRNA to sequences that are more essential to the virus than those used here, such as the sequences of active sites of virus encoded proteins which are likely to prove less likely to change by mutation. Another possibility is to target both complementary and virion-sense sequences by multiple amiRNAs. Secondly the amiRNA resistance may be "pyramided" with additional resistances that act by distinct mechanisms, making it less likely that mutation will lead to susceptibility [25].

The results of the study conducted here show that transgenic expression of an engineered amiRNA can efficiently counter infection of a monopartite begomovirus but does not lead to immunity. The ability of the expressed miRNA to deliver resistance against heterologous viruses being depended upon the levels of complementarity between the miRNA and the target is consistent with RNAi being a sequence homology-dependent phenomenon. Additionally, the sequence of the miRNA backbone was shown to influence the levels of resistance obtained.

\section{Methods}

\section{Production of amiRNA expression constructs}

The amiRNA constructs were based on the backbone sequence of the cotton pre-miR169a [13] and were synthesized by Macrogen (Korea). Synthetic amiRNA were transferred to the expression vector pJIT163 under the control of the Cauliflower mosaic virus $35 \mathrm{~S}$ promoter and nos terminator [26] as EcoR1 and HindIII fragments. Resulting expression cassettes were cloned in the binary vector pGreen0029 [27].

\section{Transformation of $N$. benthamiana and infectivity assays}

$N$. benthamiana was transformed by the leaf disc method using Agrobacterium tumefaciens GV3101 [28]. Agro bacterium-mediated inoculation of plants with $\mathrm{CLCuBuV}$ (AM421522; [8]), CLCuKoV (AJ496286; [29]), PedLCuV
(AM948961; [30]) and ToLCNDV (DNA A [U15015] and DNA B [U15017]; [31]) was conducted as previously described by infiltration using $5 \mathrm{ml}$ syringes [32].

\section{Extraction of total nucleic acids from plants and detection of viral DNA}

DNA was extracted from plants using the CTAB method [33]. Viral DNA was detected in extracts by PCR-mediated diagnostics using primer pairs IRVF/IRVR for CLCuBuV, CLCKV2F/CLCKV2R for CLCuKoV, PedLCVV2F/ PedL CuVV2R for PedLCuV and ToLCNDVV2F/ToLCNDVV2R for ToLCNDV (Table 5).

Viral DNA was detected by Southern blot hybridization essentially as described previously [34]. DNA was resolved on $1 \%$ agarose gels in $0.5 \times$ TAE buffer and transferred to nylon membrane (Hybond $\mathrm{N}+, \mathrm{GE}$ Healthcare). Blots were hybridized with viral DNA fragments produced by PCR with the primers listed in Table 5 and labeled with DIG using a PCR DIG probe synthesis kit (Roche, Switzerland) according to manufacturer's protocol.

\section{Competing interests}

The authors declare that they have no competing interests.

\section{Authors' contributions}

IrA conducted all experiments and wrote the first draft of the manuscript. ImA, SM and RWB edited the paper and coordinated the research work. All authors have read and approved the manuscript.

\section{Acknowledgements}

IrA was supported by an indigenous Ph.D scholarship from the Higher Education Commission (HEC), Government of Pakistan. RWB was supported by the HEC under the "Foreign Faculty Hiring Program". This research has also been supported by a project from the Ministry of Science and

Technology, Government of Pakistan.

Received: 6 April 2013 Accepted: 2 July 2013

Published: 12 July 2013

\section{References}

1. Bernstein E, Caudy AA, Hammond SM, Hannon GJ: Role for a bidentate ribonuclease in the initiation step of RNA interference. Nature 2001, 409:363-366.

2. Hammond SM, Bernstein E, Beach D, Hannon GJ: An RNA-directed nuclease mediates post-transcriptional gene silencing in Drosophila cells. Nature 2000, 404:293-296.

3. Meister G, Tuschl T: Mechanisms of gene silencing by double-stranded RNA. Nature 2004, 431:343-349.

4. Verdel A, Jia S, Gerber S, Sugiyama T, Gygi S, Grewal SIS, Moazed D: RNAi-Mediated targeting of heterochromatin by the RITS complex. Science 2004, 303:672-676

5. Brodersen P, Sakvarelidze-Achard L, Bruun-Rasmussen M, Dunoyer P, Yamamoto $Y Y$, Sieburth L, Voinnet O: Widespread translational inhibition by plant miRNAs and siRNAs. Science 2008, 2008(320):1185-1190.

6. Sattar MN, Kvarnheden A, Saeed M, Briddon RW: Cotton leaf curl disease-an emerging threat to cotton production worldwide. J Gen Virol 2013, 94:695-710.

7. Brown JK, Fauquet CM, Briddon RW, Zerbini M, Moriones E, Navas-Castillo J: Geminiviridae. In Virus taxonomy-ninth report of the international committee on taxonomy of viruses. Edited by King AMQ, Adams MJ, Carstens EB, Lefkowitz EJ. London, Waltham, San Diego: Associated Press, Elsevier Inc; 2012:351-373 
8. Amrao L, Amin I, Shahid S, Briddon RW, Mansoor S: Cotton leaf curl disease in resistant cotton is associated with a single begomovirus that lacks an intact transcriptional activator protein. Virus Res 2010, 2010(152):153-163.

9. Vaucheret $H$, Vazquez $F$, Crete P, Bartel DP: The action of ARGONAUTE1 in the miRNA pathway and its regulation by the miRNA pathway are crucial for plant development. Genes Dev 2004, 18:1187-1197.

10. Niu QW, Lin SS, Reyes JL, Chen KC, Wu HW, Yeh SD, Chua NH: Expression of artificial microRNAs in transgenic Arabidopsis thaliana confers virus resistance. Nat Biotechnol 2006, 2006(11):1420-1428.

11. Vu TV, Choudhury NR, Mukherjee SM: Transgenic tomato plants expressing artificial microRNAs for silencing the pre-coat and coat proteins of a begomovirus, Tomato leaf curl New Delhi virus, show tolerance to virus infection. Virus Res 2012, 172:35-45.

12. Noris E, Lucioli A, Tavazza R, Caciagli P, Accotto GP, Tavazza M: Tomato yellow leaf curl Sardinia virus can overcome transgene-mediated RNA silencing of two essential viral genes. J Gen Virol 2004, 85:1745-1749.

13. Zhang B, Wang Q, Wang K, Pan X, Liu F, Guo T, Cobb GP, Anderson TA: Identification of cotton microRNAs and their targets. Gene 2007, 397(1-2):26-37.

14. Prins M, Laimer M, Noris E, Schubert J, Wassenegger M, Tepfer M: Strategies for antiviral resistance in transgenic plants. Mol Plant Pathol 2008 9:73-83.

15. Ai T, Zhang $L$, Gao Z, Zhu CX, Guo X: Highly efficient virus resistance mediated by artificial microRNAs that target the suppressor of PVX and PVY in plants. Plant Biol 2011, 13:304-316.

16. Kung YJ, Lin SS, Huang YL, Chen TC, Harish SS, Chua NH, Yeh SD: Multiple artificial microRNAs targeting conserved motifs of the replicase gene confer robust transgenic resistance to negative-sense single-stranded RNA plant virus. Mol Plant Pathol 2011, 13:303-317.

17. Agrawal N, Dasaradhi PVN, Mohmmed A, Malhotra P, Bhatnagar RK, Mukherjee SK: RNA Interference: Biology, mechanism, and applications. Microb Mol Biol Rev 2003, 67:657-685.

18. Zhu H, Hu F, Wang R, Zhou X, Sze SH, Liou LW, Barefoot A, Dickman M, Zhang $X$ : Arabidopsis Argonaute10 specifically sequesters miR166/165 to regulate shoot apical Meristem development. Cell 2011, 145:242-256.

19. Rigden JE, Dry IB, Mullineaux PM, Rezaian MA: Mutagenesis of the virion-sense open reading frames of tomato leaf curl virus. Virology 1993, 193:1001-1005

20. Wartig L, Kheyr-Pour A, Noris E, de Kouchovsky F, Jouanneau F, Gronenborn $B$, Jupin I: Genetic analysis of the monopartite tomato yellow leaf curl geminivirus: roles of V1, V2, and C2 ORFs in viral pathogenesis. Virology 1997, 228:132-140.

21. Iqbal Z, Sattar MN, Kvarnheden A, Mansoor S, Briddon RW: Effects of the mutation of selected genes of Cotton leaf curl Kokhran virus on infectivity, symptoms and the maintenance of Cotton leaf curl Multan beta satellite. Virus Res 2012, 169:107-116.

22. Padidam M, Beachy RN, Fauquet CM: The role of AV2 ("precoat") and coat protein in viral replication and movement in tomato leaf curl geminivirus. Virology 1996, 224:390-404.

23. Sanderfoot AA, Lazarowitz SG: Cooperation in viral movement: the geminivirus BL1 movement protein interacts with BR1 and redirects it from the nucleus to the periphery. Plant Cell 1995, 7:1185-1194.

24. Manavella PA, Koenig D, Weigel D: Plant secondary siRNA production determined by microRNA-duplex structure. Proc Natl Acad Sci USA 2011, 109:2461-2466.

25. Ilyas M, Amin I, Mansoor S, Briddon RW, Saeed M: Challenges for transgenic resistance against geminiviruses. In Emerging Gemini viral diseases and their management. Edited by Sharma P, Gaur RK, Ikegami M. New York: Nova Science Publishers Inc; 2010:1-35.

26. Guerineau F, Mullineaux P: Plant transformation and expression vectors. In Plant molecular biology Lab fax. Edited by R R D Croy. Oxford: Bios Scientific Publishers; 1993:121-147.

27. Hellens RP, Edwards EA, Leyland NR, Bean S, Mullineaux PM: pGreen: a versatile and flexible binary Ti vector for Agro bacterium-mediated plant transformation. Plant Mol Biol 2000, 42:819-832.

28. Horsch RB, Fry JE, Hoffmann NL, Eichholtz D, Rogers SG, Fraley RT: A simple and general method for transferring genes into plants. Science 1985, 227:1229-1231.

29. Mansoor S, Briddon RW, Zafar Y, Stanley J: Gemini virus disease complexes: an emerging threat. Trends Plant Sci 2003, 8:128-134.
30. Ilyas M, Qazi J, Mansoor S, Briddon RW: Genetic diversity and phylogeography of begomoviruses infecting legumes in Pakistan. J Gen Virol 2010, 91:2091-2101.

31. Padidam M, Beachy RN, Fauquet CM: Tomato leaf curl geminivirus from India has a bipartite genome and coat protein is not essential for infectivity. J Gen Virol 1995, 76:25-35.

32. Hussain M, Mansoor S, Iram S, Zafar Y, Briddon RW: The hypersensitive response to tomato leaf curl New Delhi virus nuclear shuttle protein is inhibited by transcriptional activator protein. Mol Plant Microbe Interact 2007, 20:1581-1588.

33. Doyle JJ, Doyle JL: Isolation of plant DNA from fresh tissue. Focus 1990, 12:13-15.

34. Sambrook J, Frisch EF, Maniatis T: Molecular cloning: A laboratory manual. New York: Cold Spring Harbor Laboratory Press; 1989.

doi:10.1186/1743-422X-10-231

Cite this article as: Ali et al:: Artificial microRNA-mediated resistance against the monopartite begomovirus Cotton leaf curl Burewala virus. Virology Journal 2013 10:231.

\section{Submit your next manuscript to BioMed Central and take full advantage of:}

- Convenient online submission

- Thorough peer review

- No space constraints or color figure charges

- Immediate publication on acceptance

- Inclusion in PubMed, CAS, Scopus and Google Scholar

- Research which is freely available for redistribution 